\title{
From the Editor's desk
}

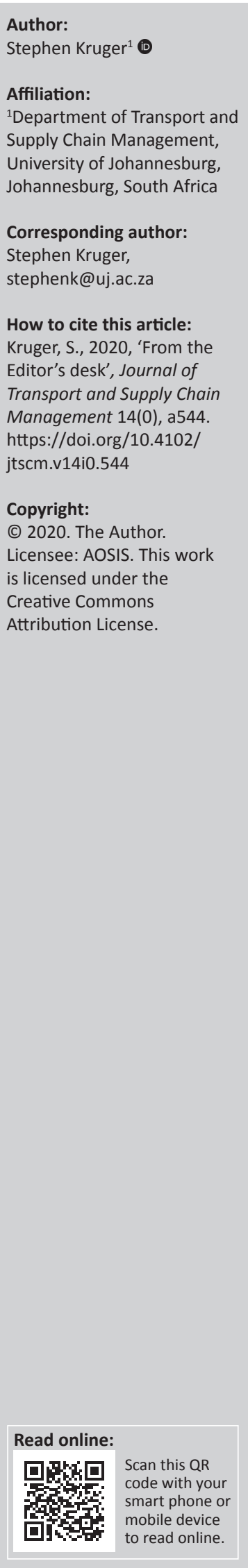

The Department of Transport and Supply Chain Management at the University of Johannesburg proudly presents to you Volume 14, 2020 of the Journal of Transport and Supply Chain Management (JTSCM), an accredited publication unique to South Africa.

\section{Fields of study}

The journal continues to serve as an independent publication for scientific contributions in the field of transportation and supply chain management.

Thanks to all the authors who have worked hard to make this an interesting and varied publication.

This edition of the journal contributes articles that have been reviewed and revised by national and international panel members who are acknowledged scholars and authors of the field.

This year, the total contribution of high-quality articles is 16 .

Articles that were submitted and approved come from the following institutions: University of Johannesburg, University of Pretoria, University of South Africa (UNISA), Durban University of Technology, Vaal University of Technology, University of KwaZulu-Natal, North-West University, University of Cape Town, Oakland University (United States of America) University of Kelaniya (Sri Lanka), University of Botswana and the University of Missouri (United States of America).

\section{A wide variety of topics are dealt with in this volume Supply chain}

Topics included in this category are exploring logistics infrastructure, humanitarian supply chain, supply chain in government, enablers, barriers and disruptions in supply chain, supply chain risks, skills framework and reverse logistics.

\section{Transport}

Topics included in this category are macro-environment impacts on commercial flights, a sustainable national airline in South Africa, a regional railway corridor, Bus Rapid Transit (BRT) air passenger movements in Sri Lanka, cause of road accidents in Botswana and travel demands of students. 